\title{
К ОПРЕДЕЛЕНИЮ ГАБАРИТОВ КАМЕРЫ РЕАКТОРА ПО ПЛАВЛЕНИЮ БАЗАЛЬТА
}

\author{
Чаймелов Андрей Александрович1, \\ chaymelovaa@ya.ru \\ Строгонов Константин Владимирович ${ }^{1}$, \\ strogonovkv@yandex.ru \\ 1 Национальный исследовательский университет «МЭИ», \\ Россия, 111250, г. Москва, ул. Красноказарменная, 14.
}

\begin{abstract}
Для развития новейших технологий энергосбережения необходимо применять эфффективные и доступные теплоизоляционные материалы. Уже долгое время, а самое главное, с большим успехом, за рубежом применяют материалы, изготовленнье из расплавов горных пород - базальтов. Базальт - самое приемлемое сырье для получения экологически чистых и, самое главное, недорогих изделий. В России наблюдается все более возрастающий интерес к изделиям на основе базальтового волокна, обусловленный бурным развитием строительства. На данный момент на территории России открыто более 300 месторождений горных пород базальтового состава. А в стратегии социально-экономического развития Северо-Кавказского Федерального округа до 2025 г. производство стройматериалов из базальта обозначено как приоритетная отрасль. Но существует и ряд проблем, которые сдерживают развитие производственных мощностей по переработке магматических пород в непрерывное базальтовое волокно, такие как поддержание постоянства температурного и химического состава расплава. Актуальной является и задача снижения энергетических затрат на плавление. В данной статье приводятся преимущества базальтового сырья для производства теплоизолирующего материала и анализируются его достоинства по сравнению с другими материалами. Описывается сущность изобретенного одним из авторов статьи реактора по плавлению базальта для изготовления непрерывного базальтового волокна, представлены сравнительные результать расчётов времени плавления базальта в данном устройстве, а также результаты времени плавления для двух разных типов расплава, приведены результаты расчета габаритов плавильной зоны реактора по плавлению базальта. Представлены результаты проведенного холодного эксперимента по времени плавления, результаты пересчета на существующий реактор.
\end{abstract}

\section{Ключевые слова:}

Плавление, базальтовое волокно, реактор, барботаж, энергоэфффективность.

\section{Введение}

В данный момент наибольший интерес для развития эффективных и доступных теплоизоляционных материалов представляют волокнистые термостойкие теплозвукоизоляционные материалы на основе магматических горных пород (базальты, диабазы габбро и др.). Главными преимуществами материалов, выполненных с применением базальтового волокна, являются доступность и низкая стоимость сырья, высокая термостойкость, низкая теплопроводность, высокая химическая устойчивость к агрессивным средам, хорошие звукоизоляционные показатели, а самое главное, экологическая безопасность как производства, так и последующей эксплуатации готового материала [1-3]. Чтобы получить такие материалы, необходимо расплавить горную породу (базальт) и далее при помощи специальных устройств (фильер) получить базальтовое волокно.

Благодаря своим уникальным свойствам базальтовое волокно и продукция на его основе все чаще находит большое применение во всех отраслях промышленности. Изделия из базальтового волокна могут выдерживать температуры до $700{ }^{\circ} \mathrm{C}$, они устойчивы к различным кислотам и щелочам, а также обладают значительной механической прочностью, они не дымят и не горят, не набирают влагу, но при этом они значительно дешевле, чем материалы на углеродном волокне [4].

Применяются материалы из базальта почти везде: в нефтегазовой и нефтехимической отрасли, строительстве, автомобильной и пищевой промышленно- сти, в производстве радиоэлектроники, машиностроении, авиа- и судостроении, в транспортных перевозках, а также в атомной промышленности.

В данной работе ставится задача по разработке методики расчета на основе физического эксперимента и теоретических исследований с их согласованием. Для этого были проведены расчёты и ряд холодных экспериментов, которые позволили рассчитать габариты плавильной зоны в зависимости от скорости движения расплава.

\section{Разработанное техническое решение}

\section{и описание метода исследования}

Наиболее энергоемким и затратным процессом в производстве базальтового волокна является процесс плавления базальта. Известны работы авторов О.Г. Волокитина и Г.Г. Волокитина, в которых рассматриваются вопросы высокотемпературного и интенсивного плавления силикатов, а также приводятся результаты физических экспериментов по получению расплава в плазмотроне [5, 6]. В настоящее время по различным источникам информации в самых современных печах по производству непрерывного базальтового волокна для плавления 1 т расплава используется более $130 \mathrm{~m}^{3}$ природного газа [7]. На промышленных печах одного из производств затрачивается 54915,38 кДж на расплав 1 т [8]. В табл. 1 представлены данные одного из существующих агрегатов на территории Российской Федерации по производству непрерывного базальтового волокна [9]. 
Таблица 1. Характеристики существующего агрегата по плавлению базальта с иелью получения непрерывных базальтовых нитей

Table 1. Characteristics of an existing basalt melting unit for production of continuous basalt filaments

\begin{tabular}{|c|c|c|}
\hline $\begin{array}{c}\text { Характеристика } \\
\text { Characteristic }\end{array}$ & $\begin{array}{l}\text { Значение } \\
\text { Value }\end{array}$ & $\begin{array}{c}\text { Единица } \\
\text { измерения } \\
\text { Unit }\end{array}$ \\
\hline $\begin{array}{l}\text { Производительность } \\
\text { Productivity }\end{array}$ & 2300 & $\begin{array}{c}\mathrm{\kappa} \Gamma / \mathrm{ч} \\
\mathrm{kg} / \mathrm{h}\end{array}$ \\
\hline $\begin{array}{l}\text { Температура расплава } \\
\text { Melt temperature }\end{array}$ & $1450-1500$ & ${ }^{\circ} \mathrm{C}$ \\
\hline $\begin{array}{l}\text { Удельный съем расплава } \\
\text { с единицы поверхности пода } \\
\text { Specific removal of the melt } \\
\text { from a unit of the hearth surface }\end{array}$ & 7000 & $\begin{array}{c}\left.\text { кг/( } \text { м }^{2} \text { сутки }\right) \\
\mathrm{kg} /\left(\mathrm{m}^{2} \text { day }\right)\end{array}$ \\
\hline Топливо/Fuel & $\begin{array}{c}\text { природный } \\
\text { газ/natural gas }\end{array}$ & - \\
\hline $\begin{array}{l}\text { Удельный расход газа } \\
\text { Specific gas consumption }\end{array}$ & 130 & $\begin{array}{l}\mathrm{M}^{3} / \mathrm{T} \\
\mathrm{m}^{3} / \mathrm{t}\end{array}$ \\
\hline $\begin{array}{l}\text { Габаритные размеры } \\
\text { Overall dimensions } \\
\text { длина/length } \\
\text { ширина/width } \\
\text { высота/height }\end{array}$ & $\begin{array}{c}16,6 \\
10,3 \\
6,0\end{array}$ & $\mathrm{M} / \mathrm{m}$ \\
\hline
\end{tabular}

Известен способ для непрерывного плавления базальта, заключающийся в том, что базальтовую шихту подают в печь, где она плавится за счет теплоты радиационного излучения. Конструкция печи имеет существенный участок подогрева базальтовой шихты, зону плавления шихты, участок расплавленного базальта и требует перегрева расплава для естественной дегазации, а с помощью фильерных установок производят непрерывные базальтовые волокна. Данный способ описан в [11].

Явным недостатком подобных устройств является большой расход энергии и отсутствие технической возможности удаления примесей (тяжелых и легких фракций) из расплава базальта. В связи с этим актуальными являются вопросы: снижения удельных затрат энергии, повышения производительности печи, улучшения качества изделия, удешевления производства и уменьшения тепловых потерь.

Для решения обозначенных выше задач на кафедpe энергетики высокотемпературной технологии Национального исследовательского университета «МЭИ» разрабатывается конструкция высокопроизводительной печи для производства непрерывного базальтового волокна (НБВ), отличительной особенностью которой является применение барботажа и зона вакуумирования для осветления расплава на участке менее 400 мм. В данном изобретении [10] в начале печи установлен конвейер для подачи шихты, далее под печи выполнен наклонным, перфорированным, с установленным под ним насосом для подачи газа, затем под выполнен горизонтальным, под которым, так же как и в торцевых стенках печи, расположена система охлаждения в виде труб, а в зоне выгрузки установлена перегородка, отделяющая зону вакуумирования с установленным в ней нагнетательным насосом. Главным же преимуществом является применение перфорированного ограждения в поду печи. Перфорация - это под, выполненный с множеством отверстий, через которые поступает газообразное топливо.

Преимущества разрабатываемой печи:

- $\quad$ это наименее энергозатратный вариант погруженного в расплав факела;

- горение и наибольшие температуры в расплаве, а не над ним, это интенсифицирует процесс нагрева и плавления;

- барботаж примерно на порядок увеличивает коэффициент теплоотдачи за счёт интенсивного перемешивания расплава;

- потеря теплоты через ограждение на данном участке фактически отсутствует, поскольку она тратиться на подогрев газовой смеси, которая поступает в реактор, тем самым осуществляется возврат энергии обратно в процесс.

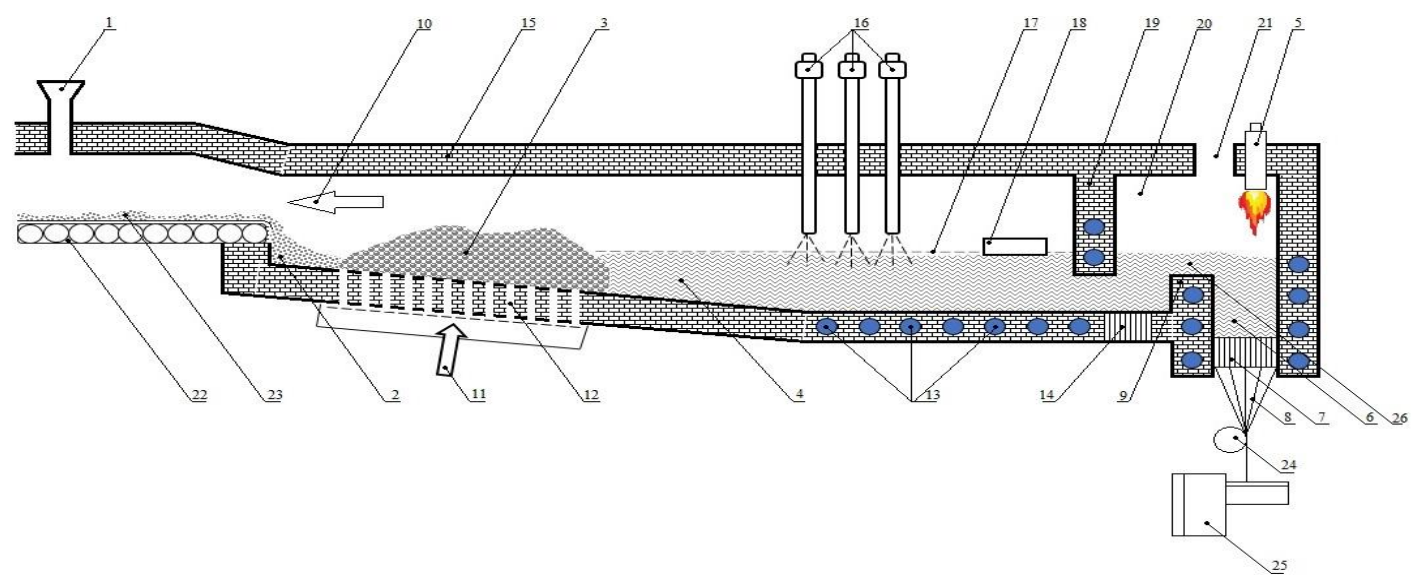

Pис. 1. Схема разрабатываемой печи: 1 - фидерная печь; 2 - бункер с дозатором и загрузчиком базальта; 3 - теплообменник; 4 -свод; 5 - горелки; 6- фильерные питатели; 7 -замасливатель; 8 -бобина; 9 - конвейер; 10 - под печи; 11 - перфорация; 12 - насос; 13 - перегородка; 14 - зона вакуумирования; 15 - нагнетательный насос; 16 - система охлаждения в виде труб; 17 - горизонтальная часть пода; 18 - ториевые стенки; 19 - отверстие

Fig. 1. Diagram of the furnace being developed: 1 -feeder furnace; 2 - hopper with a dispenser and basalt loader; 3 - heat exchanger; 4 -arch; 5 - burners; 6 -die feeders; 7 -oiler; 8 -bobbin; 9 -conveyor; 10 - hearth; 11 - perforation; 12 - pump; 13 -partition; 14 - evacuation zone; 15 -discharge pump; 16 -cooling system in the form of pipes; 17 horizontal part of the hearth; 18 -end walls; 19 - hole 
Устройство работает следующим образом: шихту по конвейеру - 9 подают в зону подогрева шихты до температур 250-600 ${ }^{\circ} \mathrm{C}$ и удаляют влагу путем подачи газа через перфорацию - 11, после чего она попадает в зону кипящего слоя. Далее она попадает в зону выравнивания температур, где с помощью теплообменника - 3 выравнивается температура расплава. В зоне происходит дегазация расплава, которая создается в зоне вакуумирования - 14, после чего расплав попадает в зону непрерывной разливки. Устанавливаются два или более щелевых или струйных фильерных питателей - 6, через которые наматывающей машиной 8 происходит вытяжка и намотка на бобины первичных непрерывных волокон. Количество фильерных питателей, установленных в фидере, может быть увеличено. Для разогрева в момент пуска и в исключительных случаях для поддержания требуемых температур расплава в фидерах на их своде установлены фидерные горелки - 5 (в нормальном, устоявшемся режиме горелки не работают).

Благодаря наличию стенки - 13 предусмотрен пережим, позволяющий организовать минимальный слой базальтового расплава для эффективной дегазации расплава в зоне вакуумирования - 14. Здесь же предусмотрено технологическое отверстие - 19 для создания разряженной атмосферы [10].

Ключевым вопросом, характеризующим габариты установки, является время плавления базальта. Расчеты включают проверку методики на моделирующем материале (лед), подтверждение на физическом эксперименте и расчеты по плавлению базальта.

\section{Физические эксперименты}

Для проверки правильности выбранной методики расчёта по определению времени плавления базальта ее результаты целесообразно сопоставить с результатами физических экспериментов.

Физические эксперименты по плавлению базальта не позволят визуально наблюдать процесс плавления и зафиксировать время, в связи с этим для проверки расчётов в первом приближении в качестве моделируемого материала был выбран лед размером 10 мм, что соответствует размерам базальта, подаваемого на плавление. Лёд имел форму усечённой пирамиды, а в расчётах принимались формулы для шара, однако опыты показали, что существенного влияния на время нагрева и плавления форма материала не оказывает. Расхождение в расчётах объясняется погрешностью визуального определения момента окончательного расплавления особенно для барботируемого расплава. Это объясняется тем, что в первоначальный период нагрева и плавления первыми оплавляются грани и расплавляемый материал фактически принимает форму шара. Поэтому для инженерных расчётов можно предполагать, что и плавление кусков дроблённого базальта одинаковых фракций можно рассчитывать по данным формулам. Физические эксперименты со льдом безопасны, наглядны, можно сделать демонстрационную установку из оргстекла. Также при выборе материала важным стало то, что базальт при попадании в расплав начинает трескаться
[11-14], то же самое происходит и со льдом, погруженным в горячую воду.

В ходе физического эксперимента было проведено 10 опытов по наблюдению за плавлением льда в барботируемой ванне. Суть эксперимента заключалась в нагреве и плавлении льда определенного диаметра с целью выяснить, за какое время кусок полностью расплавиться. В емкости объемом 3 литра было организовано кипение воды, что моделирует процесс барботажа расплава [15]. В этот сосуд с кипящей водой подавался кусок льда, одновременно начинался подсчет времени плавления. Замеры проводились такими приборами, как: термометр электронный с щупом для измерения температуры воды, секундомер для измерения времени плавления. По итогу данного физического эксперимента были получены следующие результаты (табл. 2).

Также был проведен эксперимент, в котором плавление льда проводили в горячей воде, без кипения. Такой эксперимент моделирует плавление в существующих печах ванного типа без принудительного перемешивания расплава. Суть эксперимента идентична - в горячую воду, но уже не кипящую, опускался кусок льда, и проводилось наблюдение за плавлением. Лед в этом эксперименте трескался, всплывал, но не распадался. Увеличение времени плавления связано со снижением температуры воды. Результаты, полученные для этого эксперимента, также представлены в табл. 2.

Таблица 2. Результаты физического эксперимента

Table 2. Results of a physical experiment

\begin{tabular}{|c|c|c|}
\hline \multirow{2}{*}{$\begin{array}{c}\text { № опыта } \\
\text { Experiment no. }\end{array}$} & $\begin{array}{c}\text { Спокойный расплав } \\
\text { Calm melt }\end{array}$ & $\begin{array}{c}\text { Барботируемый расплав } \\
\text { Boiling melt }\end{array}$ \\
\cline { 2 - 3 } & \multicolumn{2}{|c|}{$\begin{array}{c}\text { Bремя плавления льда, c } \\
\text { Ice melting time, } \mathrm{s}\end{array}$} \\
\hline 1 & 25,90 & 12,90 \\
\hline 2 & 25,70 & 13,07 \\
\hline 3 & 26,10 & 13,01 \\
\hline 4 & 26,10 & 13,53 \\
\hline 5 & 27,30 & 11,09 \\
\hline 6 & 29,70 & 10,47 \\
\hline 7 & 31,00 & 13,80 \\
\hline 8 & 31,50 & 10,90 \\
\hline 9 & 33,60 & 13,60 \\
\hline 10 & 35,40 & 13,50 \\
\hline Среднеe/Average & 29,23 & 12,58 \\
\hline
\end{tabular}

\section{Расчёты времени плавления}

для барботируемого расплава

Расчеты проводились в математической среде Mathcad. Для расчётов были взяты формулы авторов [16-18], которые справедливы для условий теплообмена в печах с кипящим слоем. Величина $\alpha_{s r}$ при теплообмене твердой частицы с расплавом весьма значительна: 4000-300 Вт/м²·К, благодаря чему кипящий слой расплава является средой, способной обеспечить высокую эффективность плавильных процессов [18].

Для начала необходимо было понять, каким телом является моделируемый объект

$$
\mathrm{Bi}=\frac{\alpha_{1} \cdot R}{\lambda}=0,14
$$


$\alpha_{1}$ - коэффициент теплоотдачи, который рассчитывался с помощью критерия «Nu», Вт/м² $\cdot \mathrm{K}\left(\alpha_{1}=68\right) ; R-$ радиус частицы, м $(R=0,005) ; \lambda$ - теплопроводность льда, Вт/м·К $(\lambda=2,39)[19]$.

Так как число Ві меньше 0,25 , тело является термически тонким, следовательно, дальнейший расчет времени плавления проводился для термически тонких тел.

Время нагрева льда в форме шара в барботируемом расплаве [16]:

$$
\tau_{\mathrm{H}}=\left[\ln \left[\frac{T_{v}+\alpha_{s r} T_{p l}-\left(\alpha_{s r}\right) T_{n}}{T_{v}+\alpha_{s r} T_{p l}-\left(\alpha_{s r}\right) T_{p l}}\right]\right] \frac{c \rho_{\mathrm{u}} d}{6 \alpha_{s r}} ;
$$

$T_{v}$ - температура воды, К $\left(T_{v}=361\right) ; T_{p l}$ - температура плавления частицы (льда), К $\left(T_{p l}=273\right) ; T_{n}$ - начальная температура частицы (льда), К $\left(T_{n}=255\right) ; c$ - теплоемкость частицы (льда), Дж/кг·К (c=1943) [19]; $\rho_{\text {ч }}$

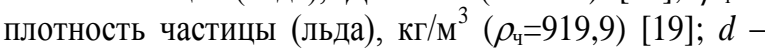
диаметр частицы (льда), м $(d=0,01)$.

Время плавления термически тонкого тела для барботируемого расплава:

$$
\begin{gathered}
\tau_{\text {пл }}=\frac{V_{\text {ше } \rho_{\text {ч }} q_{p l}}}{F_{\text {шा }} \alpha_{\text {ж }}\left(T_{\text {ос }}+T_{p l}\right)} ; \\
\tau_{\text {пл }}=4,6 \mathrm{c},
\end{gathered}
$$

где $T_{\text {ос }}$ - температура расплава (воды), К $\left(T_{\mathrm{oc}}=361\right) ; T_{p l}$ температура плавления частицы (льда), К $\left(T_{p l}=273\right)$; $q_{p l}$ - удельная теплота плавления частицы (льда), Дж/кг $\left(q_{p l}=3,3 \cdot 10^{5}\right)[20] ; \alpha_{\text {ж }}$ коэффициент теплоотдачи от жидкости к расплавляемому материалу, Вт/м² $\mathrm{K}^{2}$ $\left(\alpha_{ж}=1100\right)[21] ; \rho_{\text {ч }}-$ плотность частицы (льда), кг $/ \mathrm{M}^{3}$ $\left(\rho_{\mathrm{y}}=919,9\right)[20] ; F_{\text {ш }}$ - площадь частицы (льда), м $^{2}$ $\left(F_{\mathrm{ш}}=1,2 \cdot 10^{-3}\right) ; V_{\mathrm{ш}}$ - объем частицы (льда), ${ }^{3}\left(V_{\mathrm{ш}}=4,1 \cdot 10^{-6}\right)$.

По результатам расчета полное время плавления частицы в барботируемом расплаве составило $\tau=12,43 \mathrm{c}$.

\section{Расчёты времени плавления для ванны расплава}

\section{без принудительного перемешивания расплава}

Расчеты проводились в математической среде Mathcad. Для расчётов были взяты формулы авторов [16-18] которые справедливы для условий теплообмена в печах без принудительного перемешивания расплава.

Рассчитываем число $B i$ :

$$
\mathrm{Bi}=\frac{\alpha_{1} \cdot R}{\lambda}=0,14
$$

$\alpha_{1}$ - коэффициент теплоотдачи, который рассчитывался с помощью критерия «Nu», Вт/м ${ }^{2} \cdot \mathrm{K}\left(\alpha_{1}=68\right) ; R-$ радиус частицы (льда), м $(R=0,005) ; \lambda$ - теплопроводность льда, Вт/м·К $(\lambda=2,39)[19]$.

Так как число $B i$ меньше 0,25 , тело является термически тонким, следовательно, дальнейший расчет времени плавления проводился для термически тонких тел.

Время нагрева льда в форме шара в расплаве без принудительного перемешивания расплава [17]:

$$
\begin{gathered}
\tau_{\text {н }}=\frac{Q_{\text {шा }}}{F_{\text {шा }}\left(q_{\text {пов }}\right)} ; \\
\tau_{\text {н }}=18,5 \mathrm{c},
\end{gathered}
$$

где $Q_{ш}-$ теплота аккумуляции шара за время нагрева, Вт $\left(Q_{\Perp}=220\right) ; q_{\text {пов }}-$ плотность теплового потока, Вт/м ${ }^{2}$ $\left(q_{\text {пов }}=9,46 \cdot 10^{3}\right) ; \quad F_{\text {ш }}$ - площадь частицы (льда), м $^{2}$ $\left(F_{\text {ш }}=1,2 \cdot 10^{-3}\right)$; Время плавления шара [17]:

$$
\begin{gathered}
\tau_{\text {пл }}=\frac{R \rho_{\text {ч }} q_{p l}}{\alpha_{s r}\left(T_{\text {ос }}-T_{p l}\right)} ; \\
\tau_{\text {пл }}=10,94 \mathrm{c},
\end{gathered}
$$

где $T_{\mathrm{oc}}$ - температура расплава (воды), K $\left(T_{\mathrm{oc}}=361\right)$; $T_{p l}$ - температура плавления частицы (льда), К $\left(T_{p l}=273\right) ; q_{p l}$ - удельная теплота плавления частицы (льда), Дж/кг $\left(q_{p l}=3,3 \cdot 10^{5}\right)$ [20]; $\alpha_{s r}-$ средний коэффициент теплоотдачи, Вт/м $\mathrm{M}^{2} \cdot \mathrm{K}\left(\alpha_{s r}=3,440 \cdot 10^{3}\right)[18] ; \rho_{\mathrm{q}}-$ плотность частицы (льда), кг/м $\mathrm{M}^{3}\left(\rho_{\mathrm{y}}=919,9\right)[19] ; R-$ радиус частицы (льда), м $(R=0,005)$;

По результатам расчета полное время плавления частицы в спокойном расплаве составило $\tau=29,44$ с.

После проведенных расчетов и экспериментов доказано, что методика по расчёту времени нагрева и плавления корректна, а организация барботажного режима плавления позволяет плавить материал в два раза быстрее, поэтому данная организация плавления значительно энергоэффективнее.

Сравнивая результаты, полученные в ходе проведения эксперимента, и результаты из расчета, получаем расхождение не более в 3 \%. Отсюда можем сделать вывод, что расчетные формулы верны и теперь можно перейти к расчету плавления базальта.

Расхождение результатов для барботажного расплава:

$$
R_{1}=\frac{12,58-12,43}{12,58} \cdot 100 \%=1,19 \% .
$$

Расхождение результатов для расплава без принудительного перемешивания расплава:

$$
R_{2}=\frac{29,44-29,23}{29,44} \cdot 100 \%=0,71 \% .
$$

\section{Расчёты времени плавления базальта для барботируемого расплава}

Используя методику расчета для барботажного расплава, рассчитываем время плавления базальта и габариты печи.

Расчеты проводились в математической среде Mathcad. Для расчётов были взяты формулы авторов [16-18], которые справедливы для условий теплообмена в печах с кипящим слоем.

Значение $B i$ для базальта:

$$
\mathrm{Bi}=\frac{\alpha_{1} \cdot R}{\lambda}=0,018
$$

$\alpha_{1}$ - коэффициент теплоотдачи, который рассчитывался с помощью критерия « $\mathrm{Nu} », \mathrm{BT} / \mathrm{m}^{2} \cdot \mathrm{K}\left(\alpha_{1}=6\right) ; R-$ радиус частицы, м $(R=0,005) ; \lambda$ - теплопроводность базальта, Вт/м*К $(\lambda=1,6)[19]$. 
Так как число $B i$ меньше 0,25, тело является термически тонким, следовательно, дальнейший расчет времени плавления проводился для термически тонких тел.

Время нагрева (образования корочки) шара [16]:

$$
\begin{aligned}
& \tau_{\text {н }}=\left[\ln \left[\frac{T_{v}+\alpha_{s r} T_{p l}-\left(\alpha_{s r}\right) T_{n}}{T_{v}+\alpha_{s r} T_{p l}-\left(\alpha_{s r}\right) T_{p l}}\right]\right] \frac{c \rho_{\mathrm{u}} d}{6 \alpha_{s r}} ; \\
& \tau_{\mathrm{H}}=7,437 \mathrm{c} \text {, }
\end{aligned}
$$

где $\left(\alpha_{s r}-\right.$ средний коэффициент теплоотдачи, Вт/ $\mathrm{M}^{2} \cdot \mathrm{K}$ $\left(\left(\alpha_{s r}=1,16 \cdot 10^{3}\right) ; T_{v}\right.$ - температура газа, $\mathrm{K}\left(T_{v}=1773\right)$; $T_{p l}$ - температура плавления, К $\left(T_{p l}=1473\right) ; T_{n}$ начальная температура частицы, К $\left(T_{n}=293\right) ; c$ - теплоемкость частицы, Дж/кг·К $(c=1675)[19] ; \rho_{\text {ч }}-$ плот-

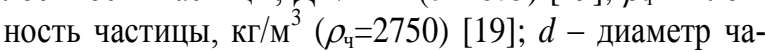
стицы, м $(d=0,01)$.

Время плавления частицы в виде шара для барботируемого расплава:

$$
\begin{gathered}
\tau_{\text {пл }}=\frac{V_{\text {ш } \rho_{\text {ч }} q_{p l}}}{F_{\text {шш }} \alpha_{\text {ж }}\left(T_{\text {ос }}+T_{p l}\right)} ; \\
\tau_{\text {пл }}=0,038 \mathrm{c},
\end{gathered}
$$

где $T_{\text {ос }}$ - температура окружающей среды, $\mathrm{K}$ $\left(T_{\mathrm{oc}}=1723\right) ; T_{p l}-$ температура плавления, К $\left(T_{p l}=1473\right)$; $q_{p l}$ - теплота плавления частицы, Дж/кг $\left(q_{p l}=2482\right)$ [22]; $\alpha_{\text {ж }}$ - коэффициент теплоотдачи от расплава к расплавляемому материалу, Вт/ $\mathrm{m}^{2} \cdot \mathrm{K}\left(\alpha_{ж}=1200\right)$ [23]; $\rho_{\mathrm{\Psi}}$ плотность частицы, кг/м ${ }^{3}\left(\rho_{\mathrm{u}}=2750\right)[19] ; F_{\text {ш }}-$ площадь частицы, м ${ }^{2}\left(V_{ш}=3,14 \cdot 10^{-4}\right) ; V_{ш}-$ объем частицы, $\mathrm{M}^{3}\left(V_{\mathrm{II}}=5,23 \cdot 10^{-7}\right)$.

\section{СПИСОК ЛИТЕРАТУРЬ}

1. Basalt.today. 2020. URL: https://basalt.today/ru/2020/06/23129/ (дата обращения: 15.08.2020).

2. Shishoo R. Technical textiles - technological and market developments and trends // Indian Journal of Fibre and Textile Research. - 1997. - V. 22. - P. 213-221.

3. Hafsa J., Rajesh M. A green material from rock: basalt fiber-a review // Journal of the Textile Institute. - 2015. - V. 107. P. 923-937.

4. John M., Thomas S. Bio fibres and bio composites // Journal of Carbohyd Polym. - 2008. - V. 71. - P. 343-364.

5. Волокитин О.Г. Физико-технические процессы получения силикатных расплавов и материалов на их основе в низкотемпературной плазме: автореф. дис. ... д-ра техн. наук. - Томск, 2016. -198 c.

6. Реализация математической модели теплопереноса в агрегате низкотемпературной плазмы при плавлении силикатных материалов / О.Г. Волокитин, Г.Г. Волокитин, Н.К. Скрипникова, В.В. Шеховцов // Вестник ТГАСУ. - 2014. - № 5. - С. 114-118.

7. S Osnos. Past, present and future of continuous basalt fiber. -2011 URL: http://www.jeccomposites.com/knowledge/internationalcomposites-news/past-present-and-future-continuous-basalt-fibre (дата обращения: 15.08.2020).

8. Basalt.today. 2018. URL: https://basalt.today/ru/2018/06/16286/ (дата обращения: 15.08.2020).

9. Новицкий А. В. Технология переработки горных пород. 2015. URL: http://novitsky1.narod.ru/bazaltfiber.htm (дата обращения: 12.07.2020).

10. Устройство изготовления непрерывных базальтовых волокон пат. Рос. Федерация № 2695188; заявл. 07.06.18; опубл. 22.07.19, Бюл. № 21. - 5 с

11. Джигирис Д.Д., Махова М.Ф. Основы производств базальтовых волокон и изделий. - М.: Изд-во «Теплоэнергетик», 2002. - 87 с.
По результатам расчета полное время плавления частицы в барботируемом расплаве составило $\tau=7,475 \mathrm{c}$ (время нагрева частицы и время плавления).

Далее, задавшись значениями производительности $(100$ кг/ч), шириной ванны $(0,30$ м) и высотой жидкого слоя расплава $(0,15 \mathrm{~m})$, была посчитана длина участка, на котором происходит нагрев и плавление базальта, которая составила $b=0,72 \mathrm{~m}$.

\section{Заключение}

В данной статье представлена методика расчета плавления базальта на основе физического эксперимента и дальнейшее исследование с ее помощью. Описана работа и представлены преимущества реактора по плавлению базальта, разработанного одним из авторов статьи на кафедре энергетики высокотемпературной технологии Национального исследовательского университета «МЭИ». Были проведены холодные эксперименты с целью выяснения реальных размеров устройства. Показано, что расчетные и экспериментальные значения по плавлению для барботажного режима отличаются на $1,19 \%$, а для плавления в ванне без принудительного перемешивания расплава $-0,71 \%$. Сопоставление расчетных данных с экспериментальными позволяет с достаточной точностью говорить о правильности методики расчета по плавлению базальта. Расчётное время нагрева и плавления куска базальта позволило в свою очередь рассчитать длину ванны печи на участке плавления, что по расчетам составило 0,72 м для производительности 100 кг/час, при этом ширина ванны принята 0,3 м, а высота слоя $-0,15 \mathrm{~m}$.

12. Basalt fiber: from earth an ancient material for innovative and modern application. - 2011. URL: https://www.enea.it/it/seguici/ pubblicazioni/EAI/anno-2011/indice-world-view-3-2011/basaltfiber-from-earth-an-ancient-material-for-innovative-and-modernapplication (дата обращения: 17.07.2020).

13. Sim J. Characteristics of basalt fiber as a strengthening material for concrete structures // International Conference on NordMin Information Day and Brokerage Event. - 2005. - P. 504-512.

14. Basalt.today. 2017. URL: https://basalt.today/ru/2017/09/12227/ (дата обращения: 15.08.2020)

15. Григорьев В.А., Зорина В.М. Промышленная теплоэнергетика и теплотехника. - М.: Изд-во «Энергоатомиздат», 1988. $433 \mathrm{c}$.

16. Попов С.К. Повышение энергетической эффективности циклонной плавильной камеры на основе исследования ее предельной производительности: автореф. дис. ... канд. техн. наук. - М., 1985. -268 c.

17. Строгонов К.В., Кузьмин В.Н. Теплотехническая оптимизация процессов в высокотемпературных теплотехнологических реакторах. - М.: Изд-во МЭИ, 2019. - 55 с.

18. Ключников А.Д., Кузьмин В.Н., Попов С.К. Теплообмен и тепловые режимы в промышленных печах. - М.: Изд-во «Энергоатомиздат», 1990. - $176 \mathrm{c}$.

19. Hassan M., Benmokrane B. Physical, mechanical, and durability characteristics of basalt FRP (BFRP) bars preliminary test results / The Fifth International Conference on Construction Materials. Canada, 2015. - P. 68

20. Теплота плавления. - 2019. URL: https://foxford.ru/wiki/fizika/ udelnaya-teplota-plavleniya/ (дата обращения: 15.09.2019).

21. Григорьев В.А., Зорина В.М. Теоретические основы теплотехники. Теплотехнический эксперимент. - М.: Изд-во «Энергоатомиздат», 1988. - 254 с. 
22. Bolasodun B., Nesbit A., Wikinson A. Effect of curing method on physical properties of araldite // International journal of scientific and Technology research. -2013 . - V. 2. - P. 12-18.
23. Ипполитов В.А. Повышение эффективности процесса плавления зернистых материалов на основе кипящего слоя расплава: автореф. дис. ... канд. техн. наук. - М., 1982. - 196 с.

Поступила: 08.09.2020 2.

\section{Информация об авторах}

Чаймелов А.А., аспирант кафедры энергетики высокотемпературной технологии Национального исследовательского университета «МЭИ».

Строгонов К.В., кандидат технических наук, доцент кафедры энергетики высокотемпературной технологии Национального исследовательского университета «МЭИ». 
UDC 621.1

\title{
DETERMINING THE DIMENSIONS OF THE REACTOR CHAMBER FOR BASALT MELTING
}

\author{
Andrey A. Chaymelov ${ }^{1}$, \\ chaymelovaa@ya.ru \\ Konstantin V. Strogonov', \\ strogonovkv@yandex.ru \\ 1 National Research University «MPEl», \\ 14, Krasnokazarmennaya street, Moscow, 111250, Russia.
}

To develop the latest energy-saving technologies, it is necessary to use effective and affordable thermal insulation materials. For a long time, and most importantly with great success, materials made from rock melts - basalts - have been used abroad. Basalt is the most acceptable raw material for producing environmentally friendly and most importantly inexpensive products. In Russia, there is an increasing interest in products based on basalt fiber, due to the rapid development of construction. At the moment, more than 300 deposits of basalt rocks have been discovered on the territory of Russia. And in the strategy of socio-economic development of the North Caucasus Federal district until 2025, the production of building materials from basalt is designated as a priority industry. However, there are also a number of problems that hinder the development of production capacities for processing igneous rocks into continuous basalt fiber, such as maintaining a constant temperature.

\section{Key words:}

Melting, basalt fiber, reactor, bubble, energy efficiency.

\section{REFERENCES}

1. Basalt.today. 2020. Available at: https://basalt.today/ru/2020/06/ 23129/ (accessed 15 August 2020).

2. Shishoo R. Technical textiles - technological and market developments and trends. Indian Journal of fiber and Textile Research, 1997, vol. 22, pp. 213-221.

3. Hafsa J., Rajesh M. A green material from rock: basalt fiber-a review. Journal of the Textile Institute, 2015, vol. 107, pp. 923-937.

4. John M., Thomas S. Bio fibers and bio composites. Journal of carbon Polym, 2008, vol. 71, pp. 343-364.

5. Volokitin O. G. Fiziko-tekhnicheskie protsessy polucheniya silikatnykh rasplavov i materialov na ikh osnove $v$ nizkotemperaturnoy plazme. Avtoreferat Dis. Dokt. nauk [Physical and technical processes for obtaining silicate melts and materials based on them in low-temperature plasma. Dr. Diss. Abstract]. Tomsk. 2016. 198 p.

6. Volokitin O.G., Volokitin G.G., Skripnikova N.K., Shekhovtsov V.V. Implementation of a mathematical model of heat transfer in a lowtemperature plasma aggregate during melting of silicate materials. Vestnik TGASU, 2014, vol. 5, pp. 114-118. In Rus.

7. Osnos S. Past, present and future of continuous basalt fiber. Available at: http://www.jeccomposites.com/knowledge/ international-composites-news/past-present-and-future-continuous-basaltfibre (accessed 15 August 2020).

8. Basalt.today. 2018. Available at: https://basalt.today/ru/2018/06/ 16286/ (accessed 15 August 2020).

9. Novitsky A.V. Tekhnologiya pererabotki gornykh porod. 2011 [Technology of rock processing]. Available at: http://novitsky1.narod.ru/bazaltfiber.htm (accessed 12 July 2020).

10. Strogonov K.V., Nazarov M.N. Ustroystvo izgotovleniya nepreryvnykh bazaltovykh volokon [Device for manufacturing continuous basalt fibers]. Patent RF, no. 2695188, 2018.

11. Dzhigiris D.D., Makhova M.F. Osnovy proizvodstv bazaltovykh volokon i izdeliy [Fundamentals of production of basalt fibers and products]. Moscow, Teploenergetik Publ., 2002. $87 \mathrm{p}$.

12. Basalt fiber: from earth an ancient material for innovative and modern application. Available at: https://www.enea.it/it/seguici/ pubblicazioni/EAI/anno-2011/indice-world-view-3-2011/basaltfiber-from-earth-an-ancient-material-for-innovative-and-modernapplication (accessed: 17 July 2020).
13. Sim J. Characteristics of basalt fiber as a strengthening material for concrete structures. International Conference on NordMin Information Day and Brokerage Event, 2005, pp. 504-512.

14. Basalt.today. 2017. Available at: https://basalt.today/ru/2017/09/ 12227/ (accessed 15 August 2020).

15. Grigoriev V.A., Zorina V.M. Promyshlennay teploenergetika i teplotekhnika [Industrial heat power engineering and heat engineering]. Moscow, Energoatomizdat Publ., 1988. 433 p.

16. Popov S.K. Povyschenie energeticheskoy effektivnosti tssiklonnoy plavilnoy kamery na osnove issledovaniya predelnoy proizvoditelnosti. Avtoreferat Dis. Kand. nauk [Improving the energy efficiency of a cyclone melting chamber based on the study of its marginal productivity. Cand. Diss. Abstract]. Moscow, 1985. 268 p.

17. Strogonov K.V., Kuzmin V.N. Teplotekhnicheskay optimizatssiya protssessov $v$ vysokotemperaturnykh teplotekhnologicheskikh reaktorakh [Heat engineering optimization of processes in high-temperature heattechnological reactors]. Moscow, MEI Publ., 2019. 55 p.

18. Klyuchnikov A.D., Kuzmin V.N., Popov S.K. Teploobmen $i$ teplovye rezimy $v$ promyshlennykh pechakh [Heat transfer and thermal modes in industrial furnaces]. Moscow, Energoatomizdat Publ., 1990. $176 \mathrm{p}$.

19. Hassan M., Benmokrane B. Physical, mechanical, and durability characteristics of basalt FRP (BFRP) bars preliminary test results. The Fifth International Conference on Construction Materials. Canada, 2015. pp. 68.

20. Teplota plavleniya [Heat of melting]. Available at: https://foxford. ru/wiki/fizika/udelnaya-teplota-plavleniya/ (accessed 15 September 2019)

21. Grigoriev V.A., Zorina V.M. Teoriticheskie osnovy teplotekhniki. Teplotekhnicheskiy eksperiment [Theoretical foundations of heat engineering. Heat engineering experiment]. Moscow, Energoatomizdat Publ., 1988. 254 p.

22. Bolasodun B., Nesbit A., Wikinson A. Effect of curing method on physical properties of araldite. International journal of scientific and Technology research, 2013, vol. 2, pp. 12-18.

23. Ippolitov V.A. Povyshenie effektivnosti protssessa plavleniya zernistykh materialov na osnove kipyashchego sloya rasplava. Avtoreferat Dis. Kand. nauk [Improving the efficiency of the melting granular materials based on a boiling layer of melt. Cand. Diss. Abstract]. Moscow, 1982. 196 p.

Received: 8 September 2020.

Information about the authors

Andrey A. Chaymelov, graduate student, National Research University «MPEI».

Konstantin V. Strogonov, Cand. Sc., associate professor, National Research University «MPEI». 